\title{
Development of a High Temperature Superconducting Controllable Reactor Based on Finite Element Method
}

\author{
M. Song \\ Yunnan Electric Power Test \& Research Group Co., Ltd. \\ Electric Power Research Institute \\ Kunming City, Yunnan Province, China
}

\begin{abstract}
A new 40kVA, 400V high-temperature superconducting (HTS) controllable reactor of transformer type has been designed, built and tested. The reactor has totally 3 windings and utilize Bi2223 HTS materials to wound the inside two windings which are responsible for the adjust of the reactor's reactance. A finite element model was developed and simulation was conducted to predict its performance, such as capacity, harmonic and response. Then experiments were carried out and results are compared.
\end{abstract}

Keywords- high temperature superconducting (HTS); finite element model; controllable reactor

\section{INTRODUCTION}

Since control of reactive power is important and significant for a transmission network, many kinds of devices are developed to cater for such demand [1]. However, most of them are characterized by one or more demerits as high harmonics component, slow response, complex control and high cost etc.[1]-[4].While Thyristor Controlled Reactor(TCR) injects lots of harmonics into the system[2], Magnetically Controlled Reactor(MCR) responses slowly and reactors of transformer type have relatively large losses[3][4].

Meanwhile, as superconducting technology develops, superconductor power equipment is expected to make a significant impact [5]. Till now, some superconducting reactors have been devised, but almost all of them are confined to fault current limiters [6][8].

Combining the technology of controllable reactor and superconductivity, this paper proposes a novel High Temperature Superconducting (HTS) controllable reactor of transformer type, which is mainly applied for reactive power compensation.

This paper applies a finite element analysis method to the computation of the reactance of the HTS reactor. A prototype of HTS reactor is built and experiments are carried out. Some discrepancies between computation and experimental results and possible causes are analyzed.

\section{BASIC PRINCIPLE}

Structure of the HTS reactor can be simplified as in fig.1. It has a three-limb core. The primary winding, i.e. the outside winding which is made up of aluminum wire, is designed to provide reactive power for system when at work, while the

\author{
Z.T. Yu, B. Sun, B.Ch. Chen, J.X. Yuan \\ School of electrical engineering, Wuhan University \\ Wuhan, Hubei Province, China
}

inside two HTS windings (secondary and tertiary winding) control the capacity of the reactor.

The primary winding being given a sinusoidal voltage, the flux traversing the HTS loop will stay invariant when HTS coil is closed according to the conservation of flux in a superconducting loop. The variant flux can only pass through the gap between the closed HTS coil and ordinary coil. Reactance changes as a result of the change of flux.

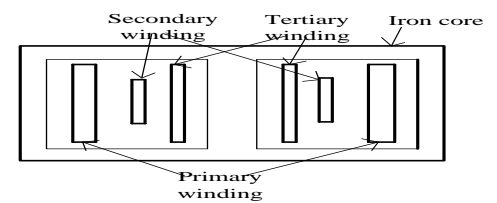

FIGURE I. STRUCTURE OF HTS REACTOR

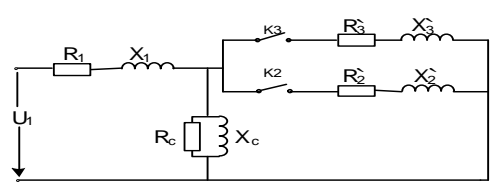

FIGURE II. EQUIVALENT CIRCUIT.

Since its structure is similar to that of a three-winding transformer, its equivalent circuit can be depicted in Fig 3. By short circuiting secondary or tertiary winding, i.e. closing switch $\mathrm{K} 2$ or $\mathrm{K} 3$, the equivalent inductance (of the primary) will vary. Its working modes are listed in Table. I.

TABLE I. WORKING MODE OF HTS REACTOR.

\begin{tabular}{|c|c|c|}
\hline Working mode & Switch status & Impedance \\
\hline S1 & K2、K3 open & $\mathrm{X} 1+\mathrm{Z} 0$ \\
\hline S2 & K2 opened,K3 closed & $\mathrm{X} 1+\mathrm{X} 3$ \\
\hline S3 & K2 closed,K3 opened & $\mathrm{X} 1+\mathrm{X} 2$ \\
\hline S4 & $\mathrm{K} 2 、 \mathrm{~K} 3$ closed & $\mathrm{X} 1+\mathrm{X} 2 / / \mathrm{X} 3$ \\
\hline
\end{tabular}

\section{COMPUTER MODELING AND SIMULATION}

Literature [9][10] proposed a finite element method, as shown in Fig.4, to calculate the reactance components of the Steinmetz exact transformer equivalent circuit. However, it is only possible for a two-winding transformer. In order to 
acquire the reactance components in Fig.2, we need to simulate for 3 times.

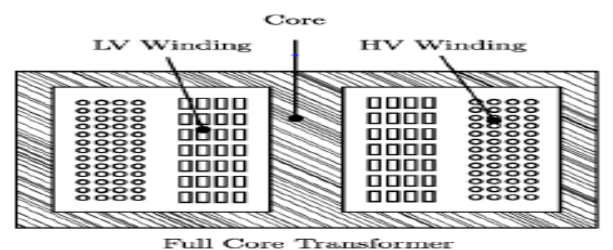

FIGURE III. FINITE ELEMENT ANALYSIS OF A FULL CORE TRANSFORMER.

That is the three windings are named $\mathrm{i}, \mathrm{j}$ and $\mathrm{k}$ respectively, three permeance matrixes for an $\mathrm{n}$ layer HTS reactor of transformer type are defined as

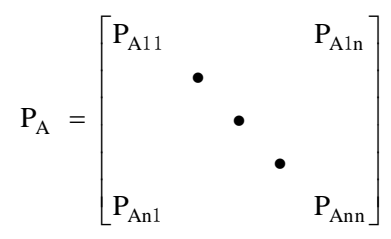

Where $\mathrm{P}_{\mathrm{Aij}}=\mathrm{P}_{\mathrm{Aji}}$

$$
\mathrm{P}_{\mathrm{B}}=\left[\begin{array}{ccccc}
\mathrm{P}_{\mathrm{B} 11} & & & & \mathrm{P}_{\mathrm{B} 1 \mathrm{n}} \\
& \bullet & & \\
& & \bullet & \\
& & \bullet & \\
\mathrm{P}_{\mathrm{Bn} 1} & & & \mathrm{P}_{\mathrm{Bnn}}
\end{array}\right]
$$

Where $\mathrm{P}_{\mathrm{Bik}}=\mathrm{P}_{\mathrm{Bki}}$

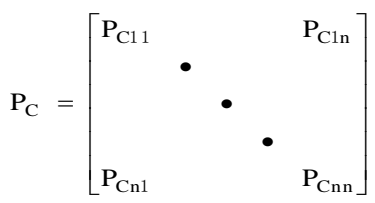

$$
\text { Where } \mathrm{P}_{\mathrm{Cjk}}=\mathrm{P}_{\mathrm{Ckj}}
$$

Each $\mathrm{P}$ is obtained from finite-element software by performing $\mathrm{n}$ simulations. In each simulation, a single winding layer, assigned with a unity number of turns, is excited with unit current, and a row of is calculated by

$$
P_{i j}=\frac{\lambda_{i}}{i_{j}}
$$

Where $\lambda_{i}$ is the flux linkage of layer due to an excitation current ${ }^{i}{ }_{j}$ in winding i. And,

$$
\begin{aligned}
& P_{i k}=\frac{\lambda_{i}}{i_{k}} \\
& P_{j k}=\frac{\lambda_{j}}{i_{k}}
\end{aligned}
$$

The winding section inductance matrix $\mathrm{L}$ can then be obtained from P. The elements of are calculated as [11]

$$
\begin{aligned}
& \mathrm{L}_{\mathrm{ij}}=\mathrm{N}_{\mathrm{i}} \mathrm{N}_{\mathrm{j}} \mathrm{P}_{\mathrm{ij}} \\
& \mathrm{L}_{\mathrm{ik}}=\mathrm{N}_{\mathrm{i}} \mathrm{N}_{\mathrm{k}} \mathrm{P}_{\mathrm{ik}} \\
& \mathrm{L}_{\mathrm{jk}}=\mathrm{N}_{\mathrm{j}} \mathrm{N}_{\mathrm{k}} \mathrm{P}_{\mathrm{jk}}
\end{aligned}
$$

Each time, two windings are selected and we call one of them primary and the other secondary. The primary and secondary windings are formed via series connections of one or more layer sections. Assume $\mathrm{W}$ is the set of winding layer sections (numbered from the inside) while $\mathrm{P}$ and $\mathrm{S}$ be subsets of containing and elements, respectively. Let $P(i)$ and $S(j)$ denote the ith and jth element of $\mathrm{P}$ and $\mathrm{S}$. The self-inductances of primary and secondary winding are then given by [12]

$$
\begin{aligned}
& \mathrm{L}_{\mathrm{Pa}}=\sum_{\mathrm{i}=1}^{n \mathrm{P}_{\mathrm{a}}} \mathrm{L}_{\mathrm{Pa}(\mathrm{i}) \mathrm{Pa}(\mathrm{i})}+\sum_{\mathrm{i}=1}^{n \mathrm{P}_{\mathrm{a}}} \sum_{\substack{\mathrm{j}=1 \\
i \neq j}}^{\mathrm{nP}_{\mathrm{a}}} \mathrm{L}_{\mathrm{Pa}(\mathrm{i}) \mathrm{Pa}(\mathrm{j})} \\
& \mathrm{L}_{\mathrm{Sa}}=\sum_{\mathrm{i}=1}^{n \mathrm{~S}_{\mathrm{a}}} \mathrm{L}_{\mathrm{Sa}(\mathrm{i}) \mathrm{Sa}(\mathrm{i})}+\sum_{\mathrm{i}=1}^{n \mathrm{P}_{\mathrm{a}}} \sum_{\substack{\mathrm{j}=1 \\
\mathrm{i} \neq \mathrm{j}}}^{n \mathrm{P}_{\mathrm{a}}} \mathrm{L}_{\mathrm{Sa}(\mathrm{i}) \mathrm{Sa}(\mathrm{j})} \\
& \mathrm{L}_{\mathrm{Pb}}=\sum_{\mathrm{j}=1}^{n \mathrm{P}_{\mathrm{b}}} \mathrm{L}_{\mathrm{Pb}(\mathrm{j}) \mathrm{Pb}(\mathrm{j})}+\sum_{\mathrm{j}=1}^{n \mathrm{P}_{\mathrm{b}}} \sum_{\substack{\mathrm{k}=1 \\
\mathrm{k} \neq \mathrm{j}}}^{n \mathrm{P}_{\mathrm{b}}} \mathrm{L}_{\mathrm{Pb}(\mathrm{j}) \mathrm{Pb}(\mathrm{k})} \\
& \mathrm{L}_{\mathrm{Sb}}=\sum_{\mathrm{j}=1}^{n \mathrm{~S}_{\mathrm{b}}} \mathrm{L}_{\mathrm{Sb}(\mathrm{j}) \mathrm{Sb}(\mathrm{j})}+\sum_{\mathrm{j}=1}^{n \mathrm{P}_{\mathrm{b}}} \sum_{\substack{\mathrm{k}=1 \\
\mathrm{k} \neq \mathrm{j}}}^{n \mathrm{P}_{\mathrm{b}}} \mathrm{L}_{\mathrm{Sb}(\mathrm{j}) \mathrm{Sb}(\mathrm{k})} \\
& \mathrm{L}_{\mathrm{Pc}}=\sum_{\mathrm{k}=1}^{n \mathrm{P}_{\mathrm{ac}}} \mathrm{L}_{\mathrm{Pc}(\mathrm{k}) \mathrm{Pc}(\mathrm{k})}+\sum_{\mathrm{k}=1}^{\mathrm{nP}} \sum_{\substack{\mathrm{i}=1 \\
\mathrm{i} \neq \mathrm{k}}}^{\mathrm{nP}_{\mathrm{c}}} \mathrm{L}_{\mathrm{Pc}(\mathrm{k}) \mathrm{Pc}(\mathrm{i})} \\
& \mathrm{L}_{\mathrm{Sc}}=\sum_{\mathrm{k}=1}^{\mathrm{nS}_{\mathrm{c}}} \mathrm{L}_{\mathrm{Sc}(\mathrm{k}) \mathrm{Sc}(\mathrm{k})}+\sum_{\mathrm{k}=1}^{\mathrm{nP}_{\mathrm{c}}} \sum_{\substack{\mathrm{i}=1 \\
\mathrm{i} \neq \mathrm{k}}}^{\mathrm{nP}_{\mathrm{c}}} \mathrm{L}_{\mathrm{Sc}(\mathrm{k}) \mathrm{Sc}(\mathrm{i})}
\end{aligned}
$$

The mutual inductance is given by,

$$
\begin{aligned}
& \mathrm{M}_{\mathrm{PaSa}}=\sum_{\mathrm{i}=1}^{\mathrm{nPa}} \sum_{\mathrm{j}=1}^{\mathrm{nSa}} \mathrm{L}_{\mathrm{Pa}(\mathrm{i}) \mathrm{Sa}(\mathrm{j})} \\
& \mathrm{M}_{\mathrm{PbSb}}=\sum_{\mathrm{j}=1}^{\mathrm{nPb}} \sum_{\mathrm{k}=1}^{\mathrm{nSb}} \mathrm{L}_{\mathrm{Pb}(\mathrm{j}) \mathrm{Sb}(\mathrm{k})} \\
& \mathrm{M}_{\mathrm{PcSc}}=\sum_{\mathrm{k}=1}^{\mathrm{nPc}} \sum_{\mathrm{i}=1}^{\mathrm{nSc}} \mathrm{L}_{\mathrm{Pc}(\mathrm{k}) \mathrm{Sc}(\mathrm{i})}
\end{aligned}
$$

Then, the inductances are transformed into the reactance components of the Steinmetz exact transformer equivalent circuit using

$$
\begin{gathered}
\mathrm{Xa}_{1}=j w\left(L_{\mathrm{Pa}}-\mathrm{xM}_{\mathrm{PaSa}}\right) \\
\mathrm{X}^{2} \mathrm{Xa}_{2}=j w x^{2}\left(L_{\mathrm{Sa}}-\frac{1}{\mathrm{x}} \mathrm{M}_{\mathrm{PaSa}}\right)
\end{gathered}
$$

Then, 
$\mathrm{Xa}=\mathrm{Xa}_{1}+\mathrm{x}^{2} \mathrm{Xa}_{2}=\mathrm{jw}\left(\mathrm{L}_{\mathrm{Pa}}+\mathrm{x}^{2} \mathrm{~L}_{\mathrm{Sa}}-2 \mathrm{xM}_{\mathrm{PaSa}}\right)$

By the same way, it can be calculated that

$$
\begin{gathered}
\mathrm{Xb}=\mathrm{Xb}_{1}+\mathrm{y}^{2} \mathrm{Xb}_{2}=\mathrm{jw}\left(\mathrm{L}_{\mathrm{Pb}}+\mathrm{y}^{2} \mathrm{~L}_{\mathrm{Sb}}-2 \mathrm{yM}_{\mathrm{PbSb}}\right) \\
\mathrm{Xc}=\mathrm{Xc}_{1}+\mathrm{z}^{2} \mathrm{Xc}_{2}=\mathrm{jw}\left(\mathrm{L}_{\mathrm{Pc}}+\mathrm{z}^{2} \mathrm{~L}_{\mathrm{Sc}}-2 \mathrm{zM}_{\mathrm{PcSc}}\right)
\end{gathered}
$$

\section{MODELING RESUlTS}

The modeling of Section II was used to design a threewinding, single-phase, 380-V, 30-kVA HTS Reactor. Table II gives the physical dimensions and materials used in the design of the reactor.

The parameters of Table II and Table III were entered into a computer program written using the modeling methods of Section II. The program was able to determine the equivalent circuit parameters for the HTS reactor design.

TABLE II. MAIN PARAMETERS OF HTS REACTOR.

\begin{tabular}{llc}
\hline parameter & value & Unit \\
\hline Rated voltage & 380 & $\mathrm{~V}$ \\
Rated current & 80 & $\mathrm{~A}$ \\
Capacity & 30 & $\mathrm{kVA}$ \\
Phase & Single & \\
Operating frequency & 50 & $\mathrm{~Hz}$ \\
Iron core & & \\
$\quad$ type & E core & \\
$\quad$ Magnetic flux density & 1.6 & $\mathrm{~T}$ \\
$\quad$ Height & 550 & $\mathrm{~mm}$ \\
\hline
\end{tabular}

TABLE III. SPECIFICS OF WINDINGS.

\begin{tabular}{lll}
\hline parameter & Designed value & Unit \\
\cline { 2 - 3 } $\begin{array}{l}\text { Primary winding } \\
\text { material }\end{array}$ & aluminum & \\
Diameter (inner/outer) & $430 / 580$ & $\mathrm{Mm}$ \\
Number of turns & 170 & $\mathrm{~mm}$ \\
Height & 410 & \\
Secondary winding & & \\
material & $\mathrm{BI}-2223$ & \\
Winding type & Circle & $\mathrm{mm}$ \\
Diameter(inner/outer) & $286 / 306$ & \\
Number of layer & 10 & $\mathrm{~mm}$ \\
Number of turns & 460 & \\
Height & 76 & \\
Tertiary winding & & $\mathrm{mm}$ \\
material & $\mathrm{BISCCO}$ & \\
Winding type & Circle & \\
Diameter(inner/outer) & $240 / 260$ & $\mathrm{~mm}$ \\
Number of layer & 12 & \\
Number of turns & 352 & \\
Height & 208 & \\
\hline
\end{tabular}

\section{EXPERIMENTS AND DISCUSSION}

Finally we built a prototype of a HTS reactor. However, in the process of manufacturing, the primary winding is built in a square shape. Experiments are carried out under 100V, 200V, $300 \mathrm{~V}, 350 \mathrm{~V}$ and $380 \mathrm{~V}$. Reactance under every experiment is calculated and listed in Table. IV.

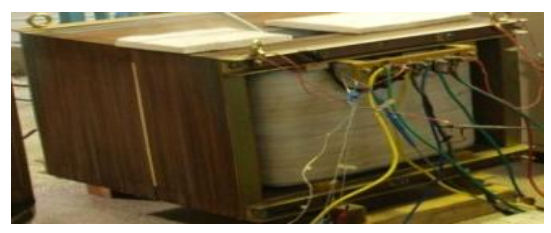

FIGURE IV. PROTOTYPE OF HTS REACTOR.

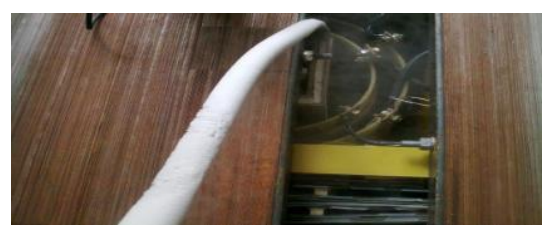

FIGURE V. WINDINGS OF THE HTS REACTOR.

TABLE IV. REACTANCE $(\Omega)$ OF HTS REACTOR.

\begin{tabular}{|l|l|l|l|l|l|l|c|}
\hline \multirow{2}{*}{} & \multicolumn{5}{|c|}{ Voltage } & \multirow{2}{*}{$\begin{array}{c}\text { Averag } \\
\text { e }\end{array}$} \\
\cline { 2 - 7 } & $100 \mathrm{~V}$ & $200 \mathrm{~V}$ & $300 \mathrm{~V}$ & $350 \mathrm{~V}$ & $380 \mathrm{~V}$ & $400 \mathrm{~V}$ & \\
\hline S1 & 454 & 800 & 600 & 290 & 211 & 181 & - \\
\hline S2 & 6.25 & 6.17 & 6.42 & 6.24 & 6.09 & 6.23 & 6.23 \\
\hline S3 & 5.46 & 5.29 & 5.61 & 5.34 & 5.22 & 5.28 & 5.37 \\
\hline S4 & 5.03 & 4.87 & 5.17 & 4.92 & 4.8 & 4.87 & 4.94 \\
\hline
\end{tabular}

TABLE V. COMPARATION OF CALCULATION SIMULATION AND EXPERIMENT (UNIT $\Omega$ ).

\begin{tabular}{|l|l|l|}
\hline & simulation & experiment \\
\hline $\mathrm{Xa}$ & 6.83 & 6.23 \\
\hline $\mathrm{Xb}$ & 5.84 & 5.37 \\
\hline $\mathrm{Xc}$ & 5.75 & 4.94 \\
\hline
\end{tabular}

From Table.V, the results of simple calculation may have a quite large error as the size of the three windings are a little irregular.

The results of simulation and experiment are generally in consistent with each other. The discrepancy between simulation and experiment are due to that the actual size of the primary winding is different from that in the model.

\section{CONCLUSION}

The inductance changing principle of high-temperature superconducting (HTS) reactor is illustrated, a finite element model is built. And electromagnetic simulation and computation is conducted and a $380 \mathrm{~V}$ experimental HTS controllable reactor was designed, based on which an experiment is conducted. Small discrepancies appeared between the simulation and experiment and the cause was analyzed.

\section{REFERENCES}

[1] Mingxing, T., L. Qingfu and L. Qunfeng, A controllable reactor of transformer type. Power Delivery, IEEE Transactions on, 2004. 19(4): p. 1718-1726.

[2] Mutluer, B., Cadirci, I,, Ermis. M., et al., "A unified relocatable SVC for opencast lignite mining in Turkey," IEEE Transactions an Industry Applications, vol.40,no.2,p p. 650 - 663,2004.

[3] A. M. Bryantsev, "Magnetic thyristor reactive power regulator," Elektrotekhnika, vol. 55, pp. 111-115, Oct. 1984. in Russian. 
[4] G. N. Aleksandrov, B. I. Al'bertinskii, and I. A. Shkuropat, "Operating principles of controllable shunt reactor of transformer type," Elektrotekhnika, vol. 66, pp. 42-47, Nov. 1995. in Russian

[5] Wass, T., S. Hornfeldt and S. Valdemarsson, Magnetic circuit for a controllable reactor. Magnetics, IEEE Transactions on, 2006. 42(9): p. 2196-2200.

[6] Yamaguchi, H. and T. Kataoka, Current Limiting Characteristics of Transformer Type Superconducting Fault Current Limiter With Shunt Impedance and Inductive Load. Applied Superconductivity, IEEE Transactions on, 2008. 18(2): p. 668-671.

[7] Hong, Z., et al., The Structure, Performance and Recovery Time of a 10 kV Resistive Type Superconducting Fault Current Limiter. Applied Superconductivity, IEEE Transactions on, 2013. 23(3): p. 56013045601304.

[8] Naeckel, O. and M. Noe, Design and Test of an Air Coil Superconducting Fault Current Limiter Demonstrator. Applied Superconductivity, IEEE Transactions on, 2014. 24(3): p. 1-5.

[9] S. C. Bell and P. S. Bodger, "Inductive reactance component model for high-voltage partial-core resonant transformers," Inst. Eng. Technol.Elect. Power Appl., vol. 2, no. 5, pp. 288-297, 2008

[10] Lapthorn, A.C., et al., HTS Transformer: Construction Details, Test Results, and Noted Failure Mechanisms. Power Delivery, IEEE Transactions on, 2011. 26(1): p. 394-399.

[11] C.-M. Ong, Dynamic Simulations of Electric Machinery: Using MATLAB/SIMULINK. Upper Saddle River, NJ: Prentice-Hall, 1997.

[12] K.Wirgau, "Inductance calculation of an air-core disk winding," IEEE Trans. Power App. Systems, vol. PAS-95, no. 1, pp. 394-400, Jan. 1976. 